\title{
$\mathrm{DMD}$ 를 이용한 마스크리스 리소그래피 시스템의 고해상도 구현을 위한 다중 빔 에너지 분석에 관한 연구
}

김종수 ${ }^{1}$, 신봉철 $^{1^{*}}$, 조용규 $^{1}$, 조명우 $^{2}$, 이수진 $^{3}$

${ }^{1}$ 인하대학교 기계공학과, ${ }^{2}$ 인하대학교 기계공학부, ${ }^{3}$ (주) 프로텍

\section{A Study on the Analysis of Multi-beam Energy for High Resolution with Maskless Lithography System Using DMD}

\author{
Jong-Su Kim ${ }^{1 *}$, Bong-Cheol Shin ${ }^{1}$, Yong-Kyu Cho ${ }^{1}$, Myeong-Woo Cho ${ }^{2}$ \\ and Soo-Jin Lee $^{3}$ \\ ${ }^{1}$ Department of Mechanical Engineering, Inha University \\ ${ }^{2}$ Division of Mechanical Engineering, Inha University \\ ${ }^{3}$ Protec corporation
}

\begin{abstract}
요 약 고 집적 회로의 제작에 있어서 노광 공정은 가장 중요한 기술로 주로 마스크 방식의 노광 방법을 사용하지 만 다품종 소량 생산 및 주기적인 제품 변화에 있어서 효율적이지 못하기 때문에 마스크리스 리소그래피 기술이 노 광공정에서 각광받고 있다. 본 연구에서는 $\mathrm{DMD}$ 를 이용한 마스크리스 리소그래피에 있어 다중 레이저 빔의 에너지와 중첩도와의 연관성을 시뮬레이션을 통해 분석하였다. 시뮬레이션을 통해 최적의 스캔 라인 간격을 제시하였고, LDI 시스템을 이용한 노광 실험을 통해 미세 페턴의 정밀도를 향상시킬 수 있었다.
\end{abstract}

\begin{abstract}
Exposure process is the most important technology to fabricate highly integrated circuit. Up to now, mask type lithography process has been generally used. However, it is not efficient for small quantity and/or frequently changing products. Therefore, maskless lithography technology is raised in exposure process. In this study, relations between multi-beam energy and overlay were analyzed. Exposure experiment of generating pattern was performed. It was from presented scan line by multi- beam simulation. As a result, optimal scan line distance was proposed by simulation, and micro pattern accuracy could be improved by exposure experiment using laser direct imaging system.
\end{abstract}

Key Words : Maskless lithography, DMD(Digital Micromirror Device), Multi beam simulation

\section{1. 서론}

정보화 시대의 도래로 전자 제품의 소형화가 요구되고 있고 이에 따라 전자 부품의 고밀도 집적화에 대한 연구 가 활발히 이루어지고 있다. 전자 부품의 고밀도 집적화 에 있어서 가장 중요한 기술은 노광 공정으로 그 종류에 는 접촉 노광, 근접 노광, 프로젝션 노광 방식으로 구분된 다. 접촉 노광과 근접 노광은 회로 패턴이 새겨진 글래스
마스크를 사용하는 방법으로 현재 가장 많이 이용되고 있다[1]. 글래스 마스크를 사용하는 노광 방식의 문제점 은 마스크 제작비용의 발생, 마스크 제조 후 유지 및 관 리 비용 발생, 마스크 불량에 의한 수율 저하, 마스크 설 계와 제작 시간의 과다 소요에 따른 생산 일정 지연 등으 로 다품종 소량 생산에 있어서 적합하지 않다. 이러한 문 제점을 개선하기 위한 방법으로 등장한 마스크리스 리소 그래피(Maskless lithography) 기술은 마스크 사용 시의

본 연구는 지식경제부와 한국산업기술진흥원의 전략기술인력양성사업으로 수행된 결과입니다.

"교신저자 : 신봉철(@)

접수일 10년 10월 19일 
문제점과 시장의 요구에 대응하도록 기존 노광 공정에 사용되던 마스크를 배제하고, 사용자가 노광용 회로패턴 데이터 파일을 입력하여 미세 패턴을 직접 노광하는 기 술이다.[2] 이러한 마스크리스 리소그래피 노광 방법은 여러 가지 종류가 있는데 그중 DMD(Digital Micromirror Device)를 이용하는 방법이 많이 부각되고 있다. 하지만 이러한 방법은 노광용 마스크 이미지를 노광패턴 조건에 최적화 시켜 $\mathrm{DMD}$ 에 픽셀형태의 래스터 이미지(Raster Image)를 전송시키고, 미러(Mirror) 피치(Pitch)간격의 공 간을 채워 최적의 노광패턴을 구현할 수 있는 방법이 필 요하다[3,4]. 또한 노광패턴을 위한 방법을 적용하여도, 최적의 노광패턴을 구현하기 위해서는 레이저 빔의 중첩 도 및 노광용 DFR (Dry Film Resist)특성 등의 다양한 변 수를 고려해야 한다.

따라서 본 논문에서는 $\mathrm{DMD}$ 를 이용한 노광 장비를 이 용하여 정밀 패턴 생성을 위하여 노광 알고리즘과 레이 저 빔의 에너지 중첩도와의 상호 관계를 통해 최적의 노 광 라인 거칠기(LER : Line Edge Roughness)를 도출하였 다. 이를 위해 이론적 시뮬레이션 결과를 토대로 노광 실 험을 실시하여 실험 결과와 이론적 내용의 일치성을 검 증하였다.

\section{2. 레이저 다중 빔 시뮬레이션}

$\mathrm{DMD}$ 를 이용한 마스크리스 리소그래피에서 스폿 사 이에는 간격이 존재하고 이로 인해 불연속적인 패턴이 생성된다. 이러한 간격을 없애기 위해 $\mathrm{DMD}$ 를 회전을 시 킨 후 노광을 수행하여 패턴을 중첩시키면 연속적인 패 턴을 생성할 수 있다[5,6]. 그러나 이미지 중첩에 있어서 알고리즘을 통한 기하학적인 이미지 처리 방법만으로는 정확한 패턴 형상을 구현할 수 없기 때문에 레이저 에너 지 특성, 사용하는 DFR 특성 등의 다양한 공정 변수를 고려해야 한다. 본 논문에서는 중첩되는 패턴 이미지의 레이저 에너지 특성을 광학 시뮬레이션을 통해 분석하고 이미지 중첩 실험을 실시하여 패턴 이미지를 분석함으로 써 연구를 진행하고자 한다.

빔 시뮬레이션 진행 조건은 광학 설계용 디자인/시뮬 레이션 소프트웨어인 $\mathrm{ASAP}$ 을 적용하여 시뮬레이션 테 스트를 표 1 의 조건으로 수행하였다.

스캔라인 간격은 레이저 빔 스폿 사이의 피치 간격을 의미하며, 이 간격이 짧을수록 노광 라인 거칠기의 형태 가 선형에 근접하는 효과가 있다. 스캔라인 간격에 따른 에너지 밀도를 분석하기 위해 그림 1 과 같이 일정 간격별 스캔라인을 정의하여 시뮬레이션을 진행하였다.
[표 1] 시뮬레이션 조건

\begin{tabular}{|l|l|}
\hline \multicolumn{1}{|c|}{ 설정 변수 } & 조건 설정 \\
\hline 광원 조건 & 가우시안 분포 \\
\hline 광 분포 영역 & 가로, 세로 $12.68 \mu \mathrm{m}$ 사각형 \\
\hline 광선 주사량 & 1.000 .000 \\
\hline 광량 & $0.00000127 \mathrm{~W}$ \\
\hline 광선 방사 방향 & 축 중심 기준 $\mathrm{X}, \mathrm{Y}$ 축으로 반각 $4^{\circ}$ \\
\hline 출력 에너지 & $\mathrm{DMD}$ 상에 $1 \mathrm{~W}$ 조사 \\
\hline 픽셀당 반사량 & $1.27 \times 10^{-6}$ \\
\hline 디텍터 측 파워 & $0.3275971 \times 10^{-6}$ \\
\hline 디텍터 측 조사량 & $0.4362717 \times 10^{-2}\left(\mathrm{~W} / \mathrm{cm}^{2}\right)$ \\
\hline 에너지 밀도 & $0.4362717\left(\mathrm{~W} / \mathrm{cm}^{2}\right)$ \\
\hline
\end{tabular}

[표 2] 폭과 광량에 따른 시뮬레이션 결과

\begin{tabular}{|c|c|c|}
\hline \multirow{2}{*}{$2 \mu \mathrm{m}$} & 중심에서의 거리 $(\mu \mathrm{m})$ & 광량 $\left(\mathrm{mW} / \mathrm{cm}^{2}\right)$ \\
\cline { 2 - 3 } & 7.125 & 98.19 \\
\hline \multirow{2}{*}{$5 \mu \mathrm{m}$} & 7.813 & 9.391 \\
\cline { 2 - 3 } & 7.094 & 33.8 \\
\hline \multirow{2}{*}{$10 \mu \mathrm{m}$} & 7.980 & 3.771 \\
\cline { 2 - 3 } & 6.283 & 93.06 \\
\cline { 2 - 3 } & 7.016 & 17.89 \\
\hline
\end{tabular}

2umpitch

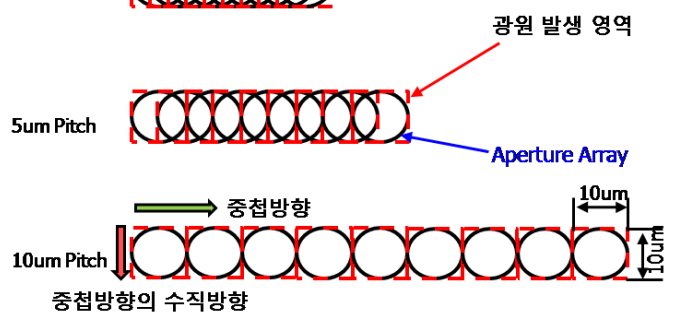

[그림 1] 중첩 시뮬레이션 방법

표 2에서 $20 \mathrm{~mJ} / \mathrm{cm}^{2}$ 의 $\mathrm{DFR}$ 을 사용할 경우 광량이 $20 \mathrm{~mW} / \mathrm{cm}^{2}$ 이상이 되어야 하고 이 지점을 라인의 선폭으 로 지정하였다. 시뮬레이션 결과 스캔 라인 간격 $2 \mu \mathrm{m}$ 인 경우 스폿 중심의 평균 광량은 $3403 \mathrm{~mW} / \mathrm{cm}^{2}$ 으로 중첩부 분의 광량은 단일 빔 스폿의 $\left(434.3 \mathrm{~mW} / \mathrm{cm}^{2}\right) 7.83$ 배의 광 량 분포도를 파악할 수 있었다.[그림 2] 이는 중첩 방향의 수직 방향으로 노광을 진행하여도 문제가 없었으며 또한 노광 라인 거칠기의 형태가 라인에 근접한 경향을 나타 내고 있다. 따라서 스캔라인 간격 $2 \mu \mathrm{m}$ 인 경우 노광 선 폭은 중심거리의 2 배인 $14.25 \mu \mathrm{m}$ 가 되는 결과를 확인할 수 있었다. 


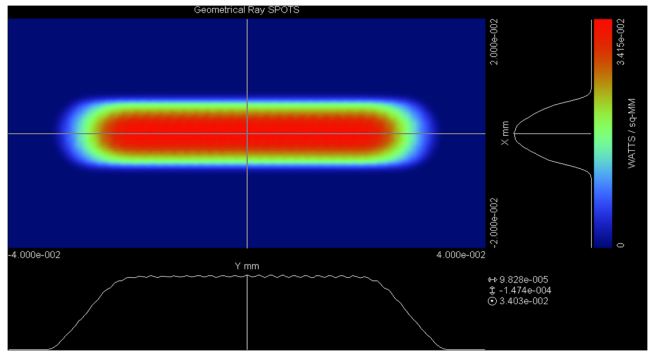

[그림 2] $2 \mu \mathrm{m}$ 시뮬레이션 결과

스캔라인 간격 $5 \mu \mathrm{m}$ 인 경우에는 스폿 중심의 평균 광 량은 $1345 \mathrm{~mW} / \mathrm{cm}^{2}$ 으로 중첩부분의 광량은 단일 빔 스폿 의 3 배의 광량 분포도를 파악할 수 있었다.[그림 3] 스캔 라인 간격 $2 \mu \mathrm{m}$ 보다는 광량 분포도가 낮으나 수직 방향 으로 노광을 진행하여도 문제가 없음을 확인할 수 있었 다. 또한 노광 라인 거칠기의 형태가 일부 단일 빔 스폿 의 형태를 나타내고는 있으나 라인에 근접한 경향을 나 타냈었고, 노광 선폭은 중심거리의 2 배인 $14.199 \mu \mathrm{m}$ 의 결과를 확인할 수 있었다.

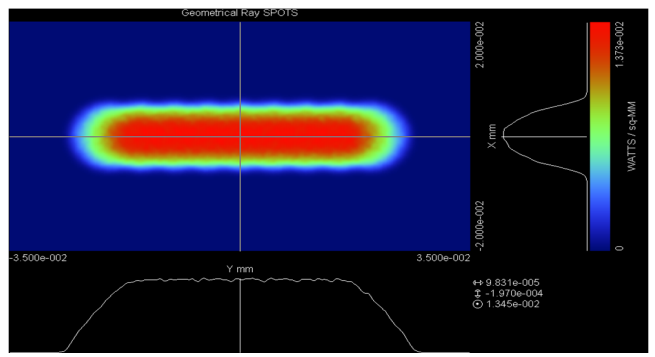

[그림 3] $5 \mu \mathrm{m}$ 시뮬레이션 결과

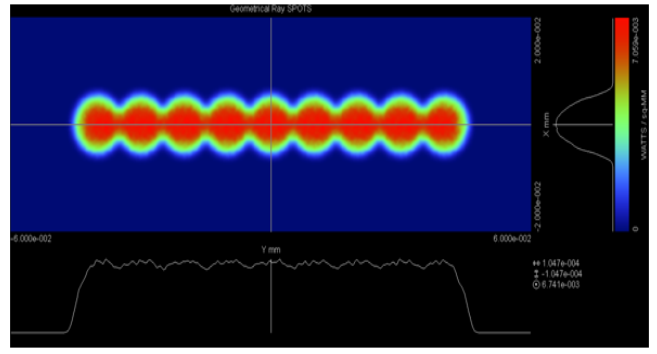

[그림 4] $10 \mu \mathrm{m}$ 시뮬레이션 결과

그림 4 는 $10 \mu \mathrm{m}$ 의 시뮬레이션 결과로 스폿 중심의 평 균 광량은 $674 \mathrm{~mW} / \mathrm{cm}^{2}$ 으로 중첩부분의 광량은 단일 빔 스폿의 1.55 배의 광량 분포도를 파악할 수 있었다. 노광 선폭은 중심거리의 2 배인 $12.566 \mu \mathrm{m}$ 으로 점차 줄어들었 고 노광 라인 거칠기의 경우에는 단일 빔 스폿의 형태로 연결 고리 모양의 경향이 나타나는 문제점이 있었다.
따라서 $10 \mu \mathrm{m}$ 에 비해 $5 \mu \mathrm{m}$ 이하에서 노광 에너지 분 포가 선형적으로 유지하는 것을 확인할 수 있었고 이 결 과를 실험에 적용하였다.

\section{3. 마스크리스 리소그래피 장치 구성}

$\mathrm{DMD}$ 기반 마스크리스 리소그래피 노광 시스템은 다 음과 같이 작동된다. $\mathrm{LED}$ 드라이버에서 조사된 UV 레이 저 소스는 광 조사 광학계를 통과하여 빔 에너지가 균일 화되고 균일화 된 빔은 $\mathrm{DMD}$ 미러에 조사되는데, $\mathrm{DMD}$ 컨트롤러에서 $1024 \times 768$ 개의 $\mathrm{DMD}$ 미러를 제어하여 레 이저 빔을 원하는 형상대로 선택적으로 프로젝션 광학계 로 반사시켜 패턴 이미지의 왜곡을 보정한 후 노광을 수 행하게 된다. 시스템의 각 구성은 다음과 같다.

본 시스템에서 사용된 UV 레이저 소스는 조사강도가 $7500 \mathrm{mw} / \mathrm{cm}^{2}$ 이고 파장대가 $365 \pm 5 \mathrm{~nm}$ 인 UV-LED를 사용 하였다. 광 조사 광학계는 일반적인 레이저 빔의 가우시 안 분포를 균일하게 하기 위해 Fly-eye lens로 빔의 손실 률을 최소화 시키고, 에너지 밀도를 Flat-Top형태로 균일 하게 제작하였다.[그림 5]

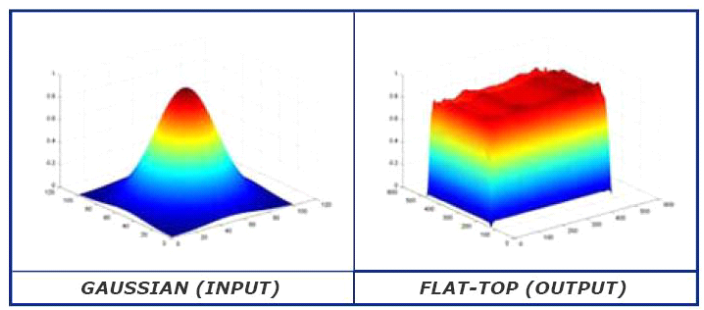

[그림 5] 레이저 빔 에너지 형태

$\mathrm{DMD}$ 는 마스크리스 노광 시스템의 핵심이 되는 부품 으로 하나의 피치 간격이 $13.68 \mu \mathrm{m}$ 인 미러가 $1024 \times 768$ 개로 배열되어 있는 텍사스 인스트루먼트(Texas Instrument)사의 제품을 사용하였다.[7] 이러한 $\mathrm{DMD}$ 는 2 개의 토션 힌지를 통해 미러가 움직이도록 구성되어 있 으며, $\mathrm{DMD}$ 컨트롤러에 의해 이진법의 전기적인 신호로 $\mathrm{On} / \mathrm{Off}$ 가 제어되어 $\pm 12^{\circ}$ 로 작동되고 $\mathrm{DMD}$ 로 입사된 빛 을 선택적으로 반사시켜 노광 패턴을 형성시킨다.[그림 $6]$

마지막으로 프로젝션 광학계는 $\mathrm{DMD}$ 에서 반사된 이 미지 패턴을 갖는 분할된 미세한 광원이 직진광이 되어 노광면에 조사 될 수 있도록 광원의 왜곡을 방지하기 위 해 텔레센트릭(Telecentric) 구조로 설계되어 있고, 여러 개의 렌즈를 사용하여 각 렌즈의 수차 특성을 서로 상쇄 
시켜 원하는 형태의 상을 만들도록 하였다.[그림 7,8]
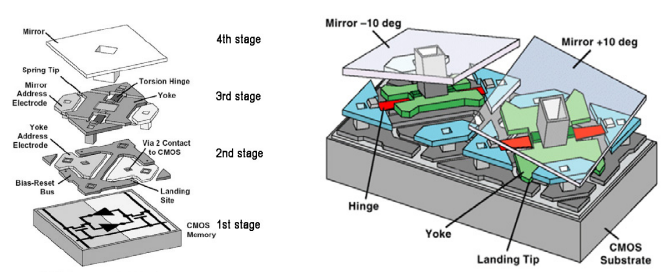

[그림 6] 마이크로 미러의 구조

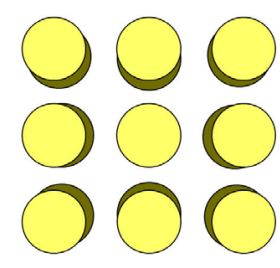

(a) General phase

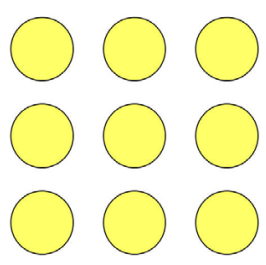

(b) Phase of telecentric lens
[그림 7] 상의 왜곡 보정

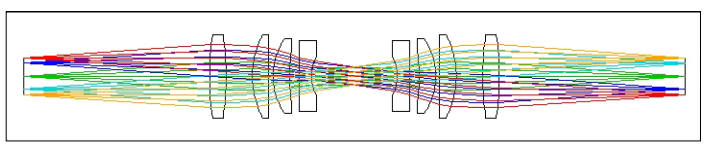

[그림 8] 프로젝션 광학계 광학 설계

시편의 정밀 이송을 위해 Newport사의 리니어 스테이 지(IMS series)를 사용하였으며, 광학계의 초점거리 도출 을 위한 스테이지 이송거리 측정은 National Instruments 사의 Motion controller(UMI-7764)를 사용하였다. 제작된 시스템은 그림 9 와 같다.
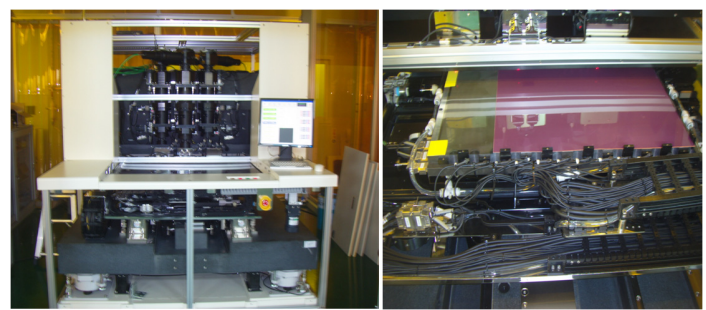

[그림 9] 마스크리스 리소그래피 시스템

\section{4. 노광 실험 및 결과}

노광에 사용된 시편은 Hitachi사의 Dry film photoresist SL-1200 series로 $355 \mathrm{~nm}$ 파장대에서 $14 \sim 23 \mathrm{~mJ} / \mathrm{cm}^{2}$ 의 에너
지 밀도의 빔이 조사될 때 반응하여 패턴을 형성한다. 현 재 구성된 시스템에서는 시뮬레이션과 같은 원형이 아닌 $\mathrm{DMD}$ 미러와 같은 사각 형태로 스폿 패턴이 형성된다. 따라서 중첩 실험은 직교방향 패턴과 대각 방향 패턴 이 미지를 $2 \mu \mathrm{m}, 5 \mu \mathrm{m}, 10 \mu \mathrm{m}$ 간격으로 중첩을 반복하여 노광을 진행하였다. 그림 10,11 과 같이 중첩시킨 이유는 단일 스폿을 중첩시켜 패턴을 생성할 경우 현상 과정과 세척 과정에서 패턴이 탈락하는 현상이 발생하여 라인 패턴을 가로 방향으로 중첩시켜 패턴을 형성한 후 패턴 의 모서리 영역을 분석하였다. 노광 후에는 $1 \% \mathrm{wt}$ 의 $\mathrm{Na}_{2} \mathrm{CO}_{3}$ 용액에서 7 분 동안 현상을 진행하였다.

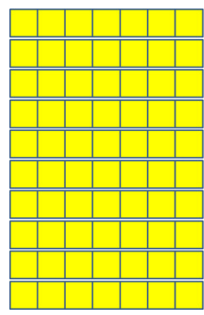

(a) $10 \mu \mathrm{m}$

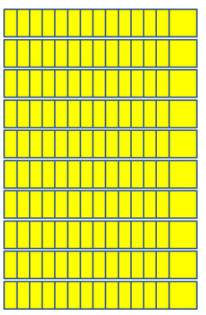

(b) $5 \mu \mathrm{m}$

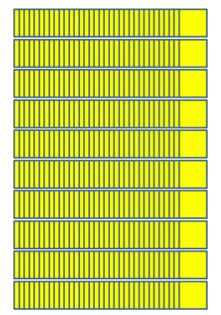

(c) $2 \mu \mathrm{m}$
[그림 10] 직교방향 중첩 패턴

실험 결과 노광 패턴이 스캔라인 간격과 중첩 형태에 따라 다르게 형성됨을 알 수 있다. $2 \mu \mathrm{m}$ 에서 직교방향 및 대각방향 패턴의 경우 패턴 형상의 모서리 부분이 둥 글게 형성되었는데 이는 중첩 영역에서 받는 빔 에너지 의 과다 노출에 기인한 것이다.

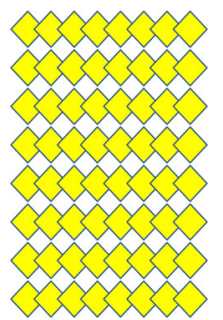

(a) $10 \mu \mathrm{m}$

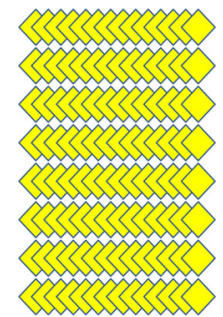

(b) $5 \mu \mathrm{m}$

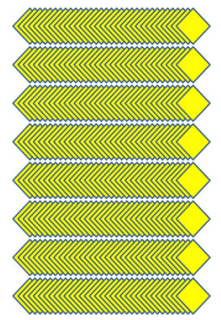

(c) $2 \mu \mathrm{m}$
[그림 11] 대각방향 중첩 패턴

$5 \mu \mathrm{m}$ 에서 $2 \mu \mathrm{m}$ 와 비슷한 라인의 모서리를 얻을 수 있지만 $2 \mu \mathrm{m}$ 의 경우 같은 길이의 패턴을 형성하기 위해 더 많은 스폿을 중첩시켜야 한다. $10 \mu \mathrm{m}$ 에서는 작은 중 첩 영역으로 인해 미러 사이에 간격 흔적이 남아있었다. [그림 12,13] 

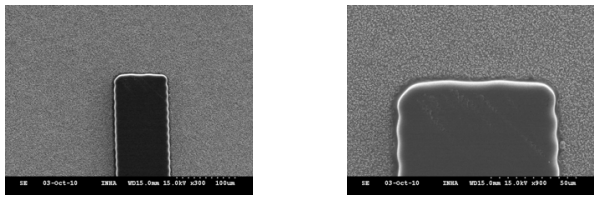

(a) $2 \mu \mathrm{m}$ scan line distance
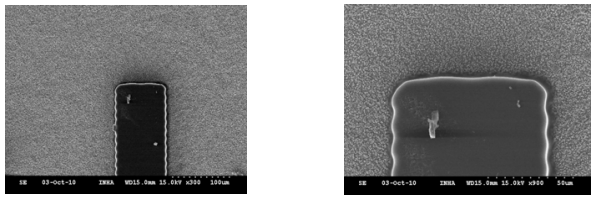

(b) $5 \mu \mathrm{m}$ scan line distance
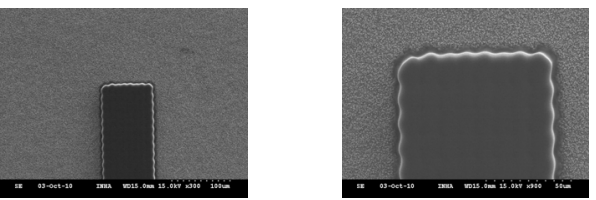

(c) $10 \mu \mathrm{m}$ scan line distance

[그림 12] 직교방향 패턴 실험 결과

직교 방향의 패턴의 경우 스캔라인 간격에 따른 패턴 의 노광 라인 거칠기의 차이가 큰 차이를 보이지 않았으 나 대각 방향의 패턴의 경우 $10 \mu \mathrm{m}$ 에서 좋지 않은 노광 라인 거칠기를 보였다. 이는 중첩 노광을 실시할 때 스캔 라인 간격을 감소시키면 노광 라인 거칠기를 좋게 만들 수 있지만 에너지의 과다 노출로 인해 둥근 모서리 윤곽 을 형성함을 알 수 있다. 따라서 스캔라인 간격을 감소시 키면 고해상도의 패턴을 얻을 수 있지만 같은 길이의 패 턴을 형성시키기 위해 중첩시켜야할 패턴의 스폿 수가 현저하게 증가하였고, 일정 간격 이하에서는 패턴 정밀도 의 향상이 크지 않음을 알 수 있었다.
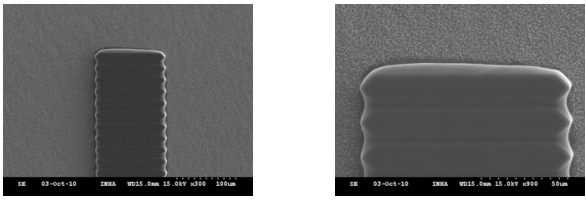

(a) $2 \mu \mathrm{m}$ scan line distance
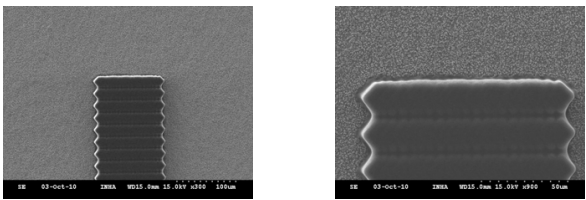

(b) $5 \mu \mathrm{m}$ scan line distance
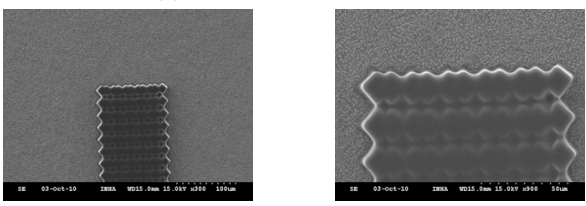

(c) $10 \mu \mathrm{m}$ scan line distance

[그림 13] 대각방향 패턴 실험 결과

\section{5. 결론}

본 연구에서는 $\mathrm{DMD}$ 를 이용한 마스크리스 리소그래 피 시스템에서 고해상도 구현을 위한 다중 빔 시뮬레이 션을 통해 에너지 분포를 분석하였고 실험을 통해 패턴 형상의 분석을 실시하였다. 실험 결과는 다음과 같다.

(1) $\mathrm{DMD}$ 를 이용한 마스크리스 리소그래피에서 미러 사이의 갭이 존재함에 따라 DMD 미러를 회전시 켜 노광 작업을 수행하게 되는데 회전 각도에 의 한 중첩도 변화를 통해서 스캔라인 간격과 해상도 가 결정된다.

(2) 레이저 빔 에너지 분석을 위하여 ASAP 프로그램 을 이용하여 스캔라인 간격별로 중첩 시뮬레이션 을 실시하여 에너지 분포를 확인하였고, 스캔라인 간격에 따른 노광 라인 거칠기를 확인하였다.

(3) 시뮬레이션을 바탕으로 광 조사 광학계, $\mathrm{DMD}$ 미 러와 컨트롤러, 프로젝션 광학계로 이루어진 시스 템을 구축하였다.

(4) 실험 결과 스캔라인 간격에 따라 중첩 패턴 형상이 시뮬레이션에서의 노광 라인 거칠기의 형태와 근 접한 결과를 확인하였고 에너지 분석과 실험을 통 해 최적의 중첩도로 $5 \mu \mathrm{m}$ 간격을 선정하였다. 시뮬 레이션 및 실험을 통해 패턴 간의 간격을 조절하여 해상도를 증가시킴으로 미세 형상의 정밀도를 향 상시킬 수 있었다.

\section{참고문헌}

[1] 홍진수, 김창교, "나노미터 크기의 임의 형상을 제작 하기 위한 새로운 리소그래피 기술”, 한국산학기술학 회논문지, Vol.5, No.3, PP.197-203

[2] 조명우, 김동우, "PCB 노광을 위한 $\mathrm{DMD}$ 를 이용한 마스크리스 리소그래피 기술”, 기계저널, Vol.50, No.6, pp.43-47

[3] M. S. Seo and H. Y. Kim, "Lithography upon micro mirrors", Computer-Aided Design, 39, 202-217, 2007

[4] 서만승, 김혜령, “마스크리스 리소그래피를 위한 점유 면적기반 패턴 생성방법”, 대한민국특허청, No. 10-2005-0114003, 2005

[5] Wehnhui Mei, "POINT ARRAY MASKLESS LITHOGRAPHY", US. Patent, No.6473237 B2, 2002

[6] Takashi Kanatake, "HIGH RESOLUTION POINT ARRAY", US. Patent, No.0004699 A1, 2004

[7] http://www.ti.com 


\section{김 종 수(Jong-Su Kim)}

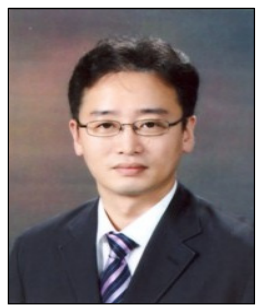

- 1993년 2월 : 안양과학대학교 제 어계측과 (전문학사)

- 2004년 2월 : 한국방송통신대학 교 컴퓨터과학과 (이학사)

- 2010년 2월 : 인하대학교 기계공 학과 (공학석사)

- 2010년 2월 현재 : 인하대학 교 기계공학과 대학원 박사과정, (주)에이원마이크로 연구소장

<관심분야>

Maskless Lithography, 마이크로 생산 시스템

\section{신 봉 철(Bong-Cheol Shin)}

[정회원]

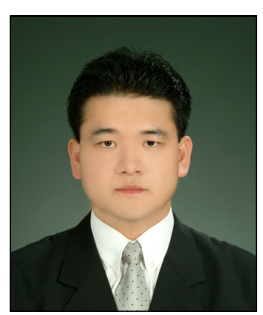

- 2000년 2월 : 호서대학교 기계공 학과 (공학사)

- 2004년 2월 : 인하대학교 기계공 학과 대학원 (공학석사)

- 2010년 2월 : 인하대학교 기계공 학과 대학원 (공학박사)

- 2010년 3월 현재 : 인하대학 교 기계공학과 박사 후 연구원

<관심분야>

마이크로 절삭 모니터링, 마이크로 $\mathrm{EDM}$, 미세 측정

\section{조 용 규(Yong-Kyu Cho)}

[준회원]

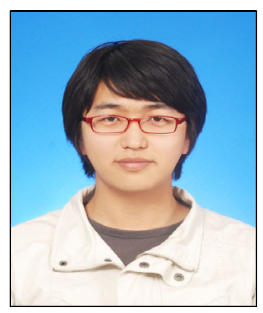

- 2010년 2월 : 인하대학교 기계공 학과 (공학사)

- 2010년 3월 현재 : 인하대학 교 기계공학과 대학원 석사과정

<관심분야>

Maskless Lithography

\section{조 명 우(Myeong-Woo Cho)}

[정회원]

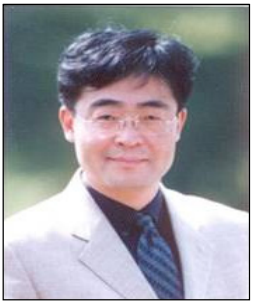

- 1983년 2월 : 서울대학교 기계설 계과 (공학사)

- 1985년 2월 : 서울대학교 기계설 계과 대학원 (공학석사)

- 1985년 1989년 : 한국생산성 본부 자동화 사업부 전문위원

- 1992년 2월 : University of Illinois (공학박사)

- 1993년 1997년 : 대우전자 시스템 사업부 부장

- 1997년 2월 현재 : 인하대학교 기계공학과 교수

<관심분야>

$\mathrm{CAD} / \mathrm{CAM} / \mathrm{CAI}$, 마이크로 생산 시스템, 머신 비전

$$
\text { 이 수 진(Soo-Jin Lee) }
$$

[정회원]

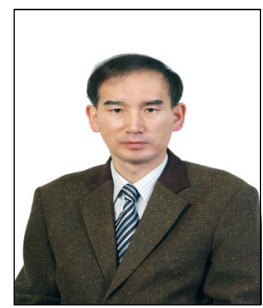

- 1990년 2월 : 한양대학교 기계공 학과 (공학사)

- 1992년 2월 : 한양대학교 기계설 계학과 대학원 (공학석사)

- 2010년 2월 :인하대학교 기계공 학과 대학원 (공학박사)

- 2002년 9월 현재 : (주)프로텍 수석연구원

<관심분야>

Maskless Lithography, LED Package 